\title{
The therapeutic process in psychodynamic therapy with children with different capacities for mentalizing
}

\begin{abstract}
Children's mentalizing capacity may influence the therapeutic process in psychodynamic therapy. The literature points to the need to tailor the therapeutic intervention to the particular configuration of clinical and developmental problems presented by the children and recommends a shift in technique in the case of severely disturbed or traumatized patients with impaired mentalizing capacity. The aim of this study was to explore the therapeutic process in psychodynamic therapy with school-age children with different kinds of difficulties and mentalizing profiles. A longitudinal design based on the systematic case study method was adopted. Three children with different baseline mentalizing capacities and their psychotherapists participated. Two hundred seventy-three psychotherapy sessions were analyzed using the Child Psychotherapy Q-Set (CPQ) in order to identify the relationship patterns between patient and therapist. Different interaction structures were identified. When the child presented with a more developed mentalizing capacity at baseline, the treatment was more similar to a standard psychodynamic approach. When mentalization capacity was impaired, more directive, supportive and empathic interventions were observed. A child's capacity for mentalization appears to impact the therapeutic process, with the adoption of certain therapeutic approaches and specific techniques depending on the child's own baseline capacity to mentalize.
\end{abstract}

Keywords: child psychodynamic psychotherapy; mentalization; interaction structures; therapeutic process; longitudinal study.

\section{Introduction}

Psychodynamic child therapy is a well-recognized treatment and there is growing evidence of its effectiveness (Abbass, Rabung, Leichsenring, Refseth, \& Midgley, 2013; Hanley \& Noble, 2017; Midgley \& Kennedy, 2011; Midgley, O’Keeffe, French, \& Kennedy, 2017; Palmer, Nascimento, \& Fonagy, 2013). Although child psychotherapy research has not received as much attention as adult psychotherapy research, an increasing number of studies have been developed, focusing on the therapeutic process with young patients (Goodman \& Midgley, 2019). However, to date, there has 
been little empirical research on how the therapeutic process, and in particular therapeutic interactions, may vary depending on the nature of the child's mental functioning.

Two decades ago, Fonagy and Target (1998) reported a detailed analysis of over 750 case records of children and adolescents, who participated in psychoanalysis and psychodynamic therapy at the Anna Freud Centre, in the United Kingdom. They found that interpretations of unconscious conflict aimed at promoting insight had limited value to the children who presented with more complex disorders, whereas for the group of less severely disturbed children, a more traditional, interpretive approach was beneficial. In the first group, designated as Cluster A, the youngsters showed fragile reality testing and thought organization, magical thinking, bizarre fantasies, mistrust, and limited relationship skills. In the second group, designated as Cluster B, the youngsters showed intense affect and hunger for social response, hyperactivity and temper tantrums.

Fonagy and Target (1998) suggested that the fundamental difference between these two groups was their capacity for reflective functioning, or what they came to call 'mentalizing'. The authors suggested that the findings of their study indicated that it would be necessary to tailor the therapeutic intervention to the particular configuration of clinical and developmental problems presented by these children. They recommended a shift in analytic technique in the case of severely disturbed or traumatized patients, with a low reflective capacity. Instead of a conflict and insightoriented approach they suggested it would be helpful to adopt a focused, mentalization-building therapy.

Mentalization is a construct that has its roots in psychoanalysis, attachment theory, developmental psychopathology and cognitive psychology (Fonagy, Bateman, \& Luyten, 2012). In order to be observed and assessed, it has been operationalized as reflective functioning (RF). Mentalizing is the capacity to understand self and others according to underlying mental states (e.g., wishes, intentions, beliefs). It develops in the context of a secure attachment relationship, and it can be implicit or explicit (i.e., automatic or controlled), based on internal or external features of self and others, directed toward the self or others, and cognitively or affectively oriented, according to Fonagy et al. (2012). It is better understood as a process instead of a fixed capacity, and it may vary according to interactional context and degree of arousal or anxiety. Difficulties with different polarities of mentalizing are an essential feature of psychological disorders, and there is some indication that 
psychotherapies may have a therapeutic effect through a benign impact on the patient's mentalizing capacity (Adshead \& Fonagy, 2012; Fonagy \& Adshead, 2012; Sharp \& Venta, 2012).

Sharp and Venta (2012) have discussed how different aspects of mentalizing are reflected in different childhood disorders. They describe difficulties of mentalizing as "no mentalizing", "undermentalizing", "hyper-mentalizing", "pseudo-mentalizing" and "distorted mentalizing". These categories refer to different types of impairments in the ability to mentalize, ranging from its absence to distortions or different levels of this ability. These authors highlighted the need to adapt therapeutic technique in response to the careful assessment of mentalizing problems in child psychotherapy.

Verheugt-Pleiter et al. (2008), building on Fonagy and Target's study (1998), have highlighted the need to change the aims of psychotherapy when children present with more complex disorders, where there underlying capacity to mentalize is limited. Nowadays, for those working with children, a manualized mentalization-based treatment exists for children (MBT-C; Midgley, Ensink, Lindqvist, Malberg, \& Muller, 2017). The aim of this treatment, more than achieving insight, is to enhance mentalizing capacity, for both the child and parents, and to promote their skills to manage emotions and relationships.

Furthermore, Muñoz Specht, Ensink, Normandin, and Midgley (2016) have shown that psychodynamic therapists working with children who have experienced early trauma or maltreatment often use mentalizing techniques in their work with these children and early adolescents. However, it is still unclear to what degree the child's basic capacity to mentalize informs the process of psychodynamic therapy with children, and whether therapists adapt their technique depending on the basic mentalizing capacity of the child.

To our knowledge, there are few empirical studies with children that have focused on this issue. Halfon, Bekar and Gürleyen (2017) compared the treatment process of two children with anxiety disorder in psychodynamic therapy. These children presented with different capacities for mentalizing before treatment. The authors found that the child who had a more explicit mentalizing ability before treatment began was able to make clinically significant change in internalizing problems at the end of the treatment. However, the therapeutic process was less traditionally psychodynamic with the child who had more significant mentalization deficits, and treatment outcomes were poorer.

Tuber (2012) has analyzed extensive clinical vignettes of two children who presented with different mentalizing characteristics. He aimed at discussing the clinical implications of these problems 
for their psychodynamic psychotherapies. One child, described as an oppositional, easily frustrated and aggressive child, was, according to the author, agnostic toward processes of mentalizing, while the other child was overtly antagonistic toward mentalizing. Emphasizing the importance of language and play in psychotherapy, and discussing in detail the therapist's interventions, Tuber showed the importance of "articulating a frame, a method, or hypothesis about the notion of being psychologically minded" (p. 13) in the first case, and of "finding a way to respond to overt challenges to any frame where self-reflection might flourish" (p. 14) in the second case. Despite the richness of this analysis, it is focused on a fragment of each psychotherapy, and not on the therapy process as a whole.

Based on these previous studies, we hypothesize that children's mental functioning, and specifically their baseline mentalizing abilities may impact the therapeutic process. Considering the characteristics of psychodynamic child psychotherapy, one could expect that when a child has developed an ability to mentalize, the child-therapist dyad will be able to focus on mental contents related to the child's conflicts and defenses. On the other hand, an impaired mentalizing ability can change the analytical process, making it necessary to approach mental processes rather than mental content, in order to help a child to face his or her psychological and relationship problems. This means that the therapist deliberately or implicitly would focus their interventions on helping the child to observe and identify his or her emotions, thoughts, wishes and so on, which is akin to a mentalizationbased approach.

The aim of this observational study was to explore the therapeutic process in psychodynamic psychotherapy with children presenting with different capacities to mentalize at baseline. We hypothesized that these different characteristics would be associated with differences in the therapeutic process, as assessed by the relationship patterns between the child and the therapist, and that psychodynamic therapies with children who have a greater mentalizing capacity will be more similar to a traditional psychodynamic approach, whereas work with children with more impaired mentalizing may lead to adaptations in ways of working and interaction structures.

\section{Method}

A longitudinal, repeated-measures design, based on the systematic case-study method (McLeod, 2010)

\section{Participants}


Three children and their three psychodynamic therapists participated in this study. We have called the three patients Alice, Peter and Walter (pseudonyms).

Alice

Alice was 8 years old when she began her psychotherapy. She was referred because of anxiety and psychosomatic symptoms. She had headaches and stomach pain with no organic causes identified. The mother sought care, referred by the daughter's neuropediatrician. Alice suddenly lost her father five months before starting psychotherapy, and the family faced financial difficulties and a change of school. She was described by the mother and the teacher as a very smart, communicative and caring girl, and also perfectionistic and afraid of making mistakes.

During the diagnostic assessment, it was observed that Alice was experiencing a state of emotional overload that limited her ability to identify and deal with affects. She struggled to exercise a strong control of affects, showed a self-centeredness and reduced interest in the outside world and in contact with the other. She was also observed to be excessively self-demanding, to have a capacity for sophisticated and complex cognitive work, and to have perfectionist characteristics.

Based on the clinical evaluation and the Rorschach Method, it was also observed that Alice revealed a good empathic ability, a trend to establish positive bonds, and an ability to reflect on her own and others' mental states. In other words, it was observed that Alice was able to mentalize, especially in the cognitive dimension of mentalization.

Alice was diagnosed with an adjustment disorder with anxiety (AD; DSM-5; American Psychiatric Association [APA], 2013), and she attended weekly 50-minute sessions for 15 months (40 sessions). Alice's psychotherapy had a break because of her therapist's maternity leave. Peter

Peter was 8 years old when he began his psychotherapy. His parents sought treatment because he did not perform his school activities, showed signs of anxiety, and was very afraid when he had to separate from his parents. He had many food restrictions, and his interests were quite limited. He was a very quiet boy who spoke little and low and was very inhibited in his play.

During the diagnostic assessment, he was observed to have significant difficulties in thought as well as distorted, confused and negative self-representations and representations of others. The Rorschach protocol was also indicative of social isolation, difficulties in processes of analysis and synthesis, and insecure and dependent behavior. He presented difficulties with identification 
processes. His difficulties in self-perception were closely related to impairments in affective processing, which indicated significant limitations in recognizing and expressing his emotions and excessively internalizing his affects, which increased his internal tension and made him emotionally and socially withdrawn. He had immature and regressive postures in his relationships, showing limitations in establishing positive bonds. Peter showed little evidence of interest in the human mind and probably a significant impairment in mentalization capacity.

Peter was diagnosed with autism spectrum disorder, level 1, without language or intellectual impairment (ASD; DSM-5; APA, 2013). Peter's psychotherapy lasted 151 sessions for 43 months.

Walter

Walter was 7 years old when he began his psychotherapy. His parents sought treatment because of his relationship difficulties and aggressive behavior at school. He had no friends and was bullied at school. He presented as very childish in his behavior and demanding.

During the diagnostic assessment, it was observed that Walter exhibited limited internal resources to deal with daily stressors, little sensitivity to his own needs and limitations in identifying internal tension, indicating difficulties in self-control. These impairments were manifested mainly in the interpersonal sphere, in difficulty in establishing positive bonds, and in relating in a superficial, dependent and less sensitive way to the needs and interests of others, making him vulnerable to rejection.

Walter exhibited a lack of confidence in himself, associated with a clearly undervalued selfimage, and an important distortion in his body image. In the affective sphere, he demonstrated a strong denial of affects, associated with hostile behaviors, with marked opposition and negativism. Such characteristics indicated the possibility of unstable and unpredictable conduct. He had no impairment in the cognitive sphere.

Considering his difficulties, the confused and distorted representations of self and others, his dependent behavior, opposition style and negativity, an impairment in his mentalizing ability was indicated. His impaired ability to modulate affect, the difficulties in the perception of self and others, in emotion regulation, and in relationships with others also supported this view.

Walter was diagnosed with disruptive mood dysregulation disorder (DMDD; DSM-5; APA, 2013). His psychotherapy lasted 158 sessions for 44 months. Therapists 
The three therapists were all female and had between two and 23 years of experience at the beginning of the treatments. Two of them were trained in psychodynamic psychotherapy; two of them held master's degrees in Clinical Psychology; and one of them held a doctoral degree in Clinical Psychology. All therapists performed individual psychoanalytic therapy and received clinical supervision during these psychotherapies.

\section{Instruments}

The Child Psychotherapy Q-Set (CPQ) - The CPQ (Schneider \& Jones, 2006, 2012) is based on Qsort methodology. It is used to analyze the psychotherapeutic process among 3- to 13-year-olds, and consists of 100 items, each containing a statement that describes a relevant feature of the treatment process corresponding to: a) the child's attitudes (i.e., feelings, behaviors, or experience); b) the therapist's actions and attitudes; and c) the nature of the patient-therapist interaction. To improve the instrument's reliability, a coding manual provides clear definitions and examples of each item, with descriptions of behaviors that might be identified from videos of sessions. After watching the videotape of the sessions, raters sort the items into nine categories, according to how characteristic each item is of the session. Forced-choice coding (ipsative) is used, establishing a normal distribution. Several studies have confirmed interrater reliability and discriminant validity of the CPQ (Goodman \& AtheyLloyd, 2011; Goodman, 2015; Goodman et al., 2016; Goodman, Reed, \& Athey-Lloyd, 2015; Ramires et al., 2015; Schmidt et al., 2018; Schneider, et al., 2010). The CPQ has been used to identify specific relationship patterns between patient and therapist, or interaction structures (ISs), in a range of diagnoses like Autism Spectrum Disorder (Goodman \& Athey-Lloyd, 2011; Ramires, Carvalho, Schmidt, Fiorini, \& Goodman, 2015), borderline personality disorder (BPD; Goodman, 2015), disruptive mood dysregulation disorder (DMDD; Ramires, Godinho, \& Goodman, 2017), adjustment disorder (AD; Schmidt, Gastaud, \& Ramires, 2018), major depressive disorder and generalized anxiety disorder (Schneider, Midgley, \& Duncan, 2010), as well as in a study of children with externalizing and internalizing problems (Halfon, Goodman, \& Bulut, 2018).

Rorschach Method - The Rorschach method is used for the exploration of the structure and dynamics of personality, and has been used in many studies to analyze changes during the therapeutic process and after termination (Bram, 2010; Exner \& Andronikof-Sanglade, 1992; Gronnerod, 2004; Heedea, Rungea, Storeboa, Rowleyb, \& Hansen, 2009; Weiner, 2004; Weiner \& Exner, 1991; Yazigi et al., 2013). It was used according to Exner's (2003) Comprehensive System (CS). Although not directly 
aimed at assessing reflective functioning, the Rorschach method was suggested as an instrument capable of clinically researching and evaluating many psychological processes involving implicit mentalization (Berant \& Zim, 2013; Conklin, Malone, \& Fowler, 2012; Pineda, Giromini, Porcelli, Parolin, \& Viglione, 2011; Porcelli \& Kleiger, 2015). Conklin et al. (2012), based on an extensive literature review, conceptually proposed that texture variables $(T)$ could reflect an individual's ability to establish attachment bonds with others; human movement responses (M) would be related to empathic ability; and the quality of the human response (GHR vs. PHR) would be related to the accuracy of perceptions about other people. The authors proposed profiles based on these Rorschach variables that describe different levels of the ability to mentalize, according to specific combinations of these variables. In this study, the Rorschach method was used to analyze children's mentalizing capacity at the onset of therapy, in addition to the clinical evaluation.

Child Behavior Check List for Children and Adolescents between 6 and 18 years of age (CBCL/6-18) and Teachers Report Form (TRF/6-18). The CBCL/6-18 and the TRF/6-18 are evidence-based instruments which are part of the ASEBA Assessment System (Achenbach System of Empirically Based Assessment) (Achenbach \& Rescorla, 1991). Their scales provide wide coverage of the psychopathological symptoms found in childhood and adolescence (Achenbach \& Ruffle, 2000). The CBCL is considered to be the most efficient quantification instrument for parental concerns about children's behavior (Wielewicki, Gallo, \& Grossi, 2011). The version of the CBCL used in this study exhibited good sensitivity (87\%), correctly identifying $75 \%$ of mild, $95 \%$ of moderate and $100 \%$ of serious cases. The CBCL protocols were completed by the children's mothers and fathers, and the TRF form by the children's teachers.

\section{Procedure}

When they came to psychotherapy, the children were assessed based on the parents' interviews, children's interviews, the CBCL and TRF forms, and the Rorschach method. Once psychotherapy was recommended, they were consulted about their participation in the research project. The therapists had previously been consulted about their availability. The study was approved by the Research Ethics Committee of the university of the first author, linked to the corresponding National Research Ethics Committee (N. 039/2012). Therapists and parents signed informed consent forms, and children provided their assent. All the sessions with children were videotaped, and they added up to 349 sessions. The psychotherapies took place in the therapists' consulting rooms. 


\section{Data Analysis}

A team of eight psychologists, trained to use the CPQ, coded 273 sessions (all sessions of Alice's and Walter's treatments were coded; one out of every two sessions of Peter's treatment was coded [n = 75]). The videos were coded in random order by two raters who were randomly assigned to and independently coded each session. Interrater reliability ranged from .62 to .81 (mean $=.73$ ). After that, the means of these assessments were calculated in order to generate the composite score, which was used subsequently.

The composite scores were submitted to a principal components factor analysis to determine the relationship patterns of each psychotherapy, or, in other words, the interaction structures (ISs). Pearson correlations were used to analyze whether the ISs changed over time. All statistical analyses in the study were performed using SPSS 23.0.

The Rorschach protocols were independently coded by two trained psychologists and subsequently compared. The intraclass correlation coefficients ranged from .97 to .99 (mean $=.98$ ). The interpretation of the results in each Rorschach variable was based on normative data for the population under study (Ribeiro, Semer, \& Yazigi, 2012). The criterion used to interpret the results was one standard deviation above or below average.

\section{Results}

In this study, we analyzed the psychotherapies of three children who presented predominantly with difficulties in three different spheres: internalizing symptoms, externalizing symptoms, and a developmental disorder. Alongside these difficulties, their mentalization capacities at psychotherapy onset were varied. The Rorschach assessments led to the development of a mentalizing profile for each child, which can broadly be described as "able to mentalize" (Alice), "mentalization impairments" (Walter) and "significant mentalization impairments" (Peter). We provide detailed information on these assessments and the corresponding Rorschach variables in the Appendix.

The therapeutic processes of these children were analyzed focusing on the relationship patterns between patients and therapists, conceptualized as interaction structures (ISs). To determine these ISs we performed a principal components factor analysis, that yielded four conceptually distinct factors in Peter's and Walter's treatments. In Alice's psychotherapy we identified five distinct factors. These factors explained $36.9 \%, 37.3 \%$ and $31.9 \%$ of the variance of the items in Alice's, Peter's and Walter's treatments, respectively, which is consistent with the literature (Goodman, 2015; Goodman \& 
Athey-Lloyd, 2011; Ramires et al., 2015; 2017; Schmidt et al., 2018). The factors were conceptualized as ISs, describing repetitive patterns of interaction between each therapeutic dyad. Table 1 summarizes these ISs, their internal consistency, and changes over time.

[Table 1 near here]

\section{Discussion}

We can observe that differences in children's difficulties and in their baseline mentalizing capacity seem to be associated with differences in the therapeutic process, as assessed by the interaction structures between the patient and therapist. The three psychotherapies were all psychodynamic treatments. However, we found indicators that the therapists probably had to adapt their interventions to respond to the children's needs and difficulties, sometimes moving away from the standard technique of psychodynamic therapy.

Unlike the other psychotherapies, in Alice's treatment we observed an attuned and interpretive therapist interacting with an expressive child (IS 1), and this relationship pattern had increased over the psychotherapy $(r=.41, p<.01)$. We also observed a sensitive, supportive and receptive therapist interacting with a distant or anxious girl (IS 2 and 5). In the IS 5 (receptive and supportive therapist with an anxious child), the IS became more characteristic $(r=.35, p<.05)$, and we should remember that this patient had suddenly lost her father and had to face the therapist's maternity leave. We hypothesize that these factors could help to explain the relationship patterns in which Alice was aggressive and defensive (IS 3) or dependent and resistant (IS 4), when the therapist acted in a more directive and limiting way, although the IS 4 became less characteristic over time $(r=-.53, p<.01)$.

Overall Alice's psychotherapy, according to the identified ISs, was similar to a traditional psychodynamic approach. Considering her psychic resources and a therapist with an accurate understanding of the therapeutic process, it was possible for her therapist to analyze and formulate an understanding of her unconscious conflicts and contents.

Walter presented with very disruptive behavior and emotional dysregulation, and his mentalizing capacity was impaired at psychotherapy onset. Only IS 3 became significantly more characteristic over time $(r=.78, p<.01)$. It describes a "CBT-style" therapist, which may have been necessary in order to help an impulsive and dysregulated child with limited mentalizing capacity. Items pertaining to the cognitive-behavioral therapy model described by Goodman et al. (2016) were present in this IS, like item 57 (therapist attempts to modify distortions in child's beliefs) and item 27 (there is a 
focus on helping child plan behavior outside the session). The therapist also directly rewarded desirable behaviors (item 55), was directly reassuring (item 66), and informed the child of the potential impact of his behavior on others (item 87), among other items.

We can also observe in this psychotherapy the interactions between a connected and expressive child and a supportive therapist (IS 1), a sensitive and accepting therapist with an understood child (IS 2), and a demanding and blaming child with a supportive therapist (IS 4). These three relationship patterns were consistent across the treatment, and they seemed to be related to a very emotionally dysregulated child who needed containment and a framework that, to some extent, enabled the experience of being recognized and contained in his therapist's mind. We did not observe, in the ISs, an interpretive therapist, as in Alice's treatment, which suggests that the focus on explicit mentalizing was less part of this therapy.

Peter, the boy diagnosed with ASD, presented with significant impairment in his mentalizing capacity at psychotherapy onset. In cases like this, the literature has stated the need to adopt a focused, mentalization-oriented therapy (Fonagy \& Target, 1998; Verheugt-Pleiter, 2008; Midgley et al., 2017). Two ISs in Peter's treatment corroborate the role of such an approach in the psychotherapy process. IS 2 (active, confident and lively child, competing with connected and reflective therapist) suggests a mentalizing approach becoming more characteristic over time $(r=.39, p<.01)$. On the other hand, IS 1 (resistant and defensive child with uncertain, unresponsive and didactic therapist) decreased over time $(r=-.52, p<.01)$ and suggests a relationship pattern in which a reflective functioning was gained by the therapist and the child, and we hypothesize that the child's difficulties in mentalizing may have initially had an impact on the therapist's mentalizing capacity. Probably, when the therapist was able to figure out what was going on and recovered this capacity, she was effective in helping the boy to slowly start to mentalize, and we could observe a change in the interaction patterns in the later phases of this treatment.

Walter and Peter's treatments were the longest and showed greater variability in the quality of their relationship patterns. Children who present with disruptive behavior and autism spectrum difficulties usually show significant impairment in reflective capacity and hence impairments in emotional regulation (Goodman, 2015; Goodman \& Athey-Lloyd, 2011; Hoffman, Rice, \& Prout, 2016). In Walter's case, these impairments were reflected in uncontrolled behaviors, feelings of being misunderstood, and difficulties in reflecting on his conflicts. In Peter's case there was a mental 
impermeability and a total lack of awareness of mental states of self and others. More directive strategies are used when there are moments of no mentalization during the sessions. At such times, it is important for the therapist to focus on points where the mentalization was lost, to help the patient to explore and think about what happened (Fonagy et al., 2014).

Directive ISs were observed in all treatments in this study. In Walter's case, such ISs became significantly more characteristic (IS 3), and we would suggest that it was necessary, considering his disruptive behavior and dysregulated emotions. Such directive strategies are common with more regressive patients like Peter, or patients who show affective outbursts like Walter. Children with limited internal resources demand the therapist's flexibility to adapt to their needs (Hoffman et al., 2016).

Hence, children might need a different approach depending on their presentation in a particular session, which has been observed previously in the literature (e.g., Goodman, 2015; Goodman \& Athey-Lloyd, 2011). As different children may need different approaches, the same child may need different techniques in different therapeutic moments. Another interpretation might be that countertransference pressures pushed the therapists "off-model" such that they were induced at various moments to be more controlling or directive in the sessions. Maybe more directive strategies were used when there were moments of no mentalization during the sessions. It would be necessary to conduct time series analysis to identify whether directive strategies precede or follow these moments, and who initiates such non-mentalizing moments: the therapist or the child.

Muñoz Specht et al. (2016) had examined the mentalizing techniques used by psychodynamic therapists in their work with children, and had categorized such interventions into three main groups: "supporting mentalization-stance interventions", "basic mentalizing techniques", and "mentalizing the play context". In the first type, the authors described therapeutic framework interventions, supportive and empathic interventions, exploration and clarification techniques and psychoeducation, which are not directly mentalization-focused, but which are necessary to stimulate a mentalizing stance. For instance, when applying therapeutic framework interventions, the therapist may address the rules, the therapeutic contract and the limits. We can observe these kinds of interventions in Walter's IS 3 and even in Alice's IS 3 and 4, in this case probably when her arousal levels were higher. Supportive and empathic interventions were present in all treatments: IS 2 and 5 in Alice's psychotherapy; IS 3 and 4 in Peter's psychotherapy; and IS 1, 2, and 4 in Walter's psychotherapy. Depending on the children's 
state of dysregulation and mentalizing abilities, therapists should adapt their interventions, in order to put the therapeutic process back on track. In contrast, mentalizing techniques themselves, as described by Muñoz Specht et al., were more frequently identified in Alice's psychotherapy, notably in IS 1.

Muñoz Specht et al. (2016) also highlighted that, besides mentalizing abilities, the type of disorder may have an impact on the interventions used by therapists. Research has shown that children's responses to psychodynamic treatments depend on their age, type of symptoms and symptom severity (Halfon et al., 2018; Midgley \& Kennedy, 2011; Midgley et al., 2017).

\section{Limitations of this study}

This observational and exploratory study has some limitations which must be pointed out. We only examined the role of children's mentalizing abilities and the role of the interaction structures in the therapeutic process. We did not examine other patient factors like characteristics of each diagnosis and their impact on the treatments, defense mechanisms, or therapists' characteristics like mentalizing capacity, personality traits, or even other elements of the therapeutic process like therapeutic alliance, transference and countertransference, and so on. These variables may also help to explain the observed characteristics of these therapeutic relationships. Moreover, the treatments also differed in their length, the therapists' previous experience, and the children's diagnoses. Future process research with more rigorous controls in place can study valuable information regarding the role of different variables in explaining interaction structures, adherence to therapeutic models, and therapeutic change in child PDT.

We did not use a standard measure to assess children's baseline mentalizing capacities. The primary aim of the Rorschach method is not to assess mentalizing capacity, and it only allows for a global assessment of this ability, related to the implicit dimension of mentalizing. Future studies based on standard measures may explore specific aspects of children's mentalizing abilities and the therapeutic process not examined in this investigation.

We also should consider that the CPQ is a broadband instrument, and is not designed to capture the nuances of mentalization, such as whether the therapist is working with "explicit mentalizing", or intervening to help establish the "building blocks" of mentalization, for those children with a lower baseline capacity to mentalize, as recommended by Midgley et al. (2017). 
It is important to highlight that we are not suggesting a causal relationship between baseline mentalization and treatment process. There are numerous factors that were not controlled for in this study, and these factors could also explain these findings. Considering the aim and design of this study, we are not able to determine whether children's type of disorder (internalizing, externalizing or developmental) or their mentalizing capacity at psychotherapies' onset had a greater impact on the therapeutic relationship patterns and therapist techniques. Halfon et al. (2018) found some evidence that therapists' techniques are part of a complex interaction with the children's characteristics. As in their research, the present study observed that children's characteristics, which probably included their type of disorder and mentalizing abilities, were related in different ways to the therapeutic relationship over the course of treatment.

\section{Conclusion}

The findings of this study suggest that when a child presents with an impaired mentalizing capacity, this impairment can hinder the progress of the therapeutic process in general, until some capacity to reflect on mental states can be enhanced. On the other hand, if some mentalizing ability is present, a psychodynamic approach is likely to be followed more closely.

This study corroborated the literature, which considers mentalization as an important aspect in psychodynamic therapeutic process (Goodman et al., 2015; Goodman et al., 2016; Halfon \& Bulut, 2019; Halfon et al, 2017; Muñoz Specht et al., 2016; Tessier et al., 2016). The findings support the hypothesis that a child's baseline mentalizing capacity should be one factor, among others, to be taken into account in explaining the differences among these therapeutic processes. Future studies could explore if improving mentalization would contribute to a change in the direction of the therapeutic process, in terms of a more insight-oriented approach and vice versa, in a feedback loop, and the role of other techniques as well. That would require repeated measures to assess children's mentalizing capacity across treatment.

The results of this study lead us to consider that mentalizing can be thought of as an individual capacity (even if it is not fixed) and as an important factor in shaping the therapeutic process. It can play a different role in the therapeutic process, depending on the child's characteristics and diagnosis, probably becoming more salient in treatment the more regressive and emotionally dysregulated the child. Whilst more traditional psychodynamic techniques may be found in the treatment of children who already have a basic capacity to mentalize, it may be that psychodynamic therapists working with 
children with greater impairments in mentalizing are likely to draw on a broader range of ways of working, including more directive, supportive and empathic interventions.

Acknowledgments - The authors thank the National Council for Scientific and Technological Development of Brazil (grants 309544/2017-3 and 422602/2018-3) and the CAPES Foundation, Ministry of Education of Brazil, for supporting this study.

Declaration of interest statement - There was no conflict of interest in the development of this study.

\section{References}

Abbass, A. A., Rabung, S., Leichsenring, F., Refseth, J. S., \& Midgley, N. (2013). Psychodynamic Psychotherapy for Children and Adolescents: A Meta-Analysis of Short-Term Psychodynamic Models. Journal of the American Academy of Child \& Adolescent Psychiatry, 52(8), 863-875. doi: 10.1016/j.jaac.2013.05.014.

Achenbach, T.M. \& Rescorla, L.A. (1991) Manual for the ASEBA School-Age Forms \& Pro- files. Burlington, VT: University of Vermont, Research Center for Children, Youth, \& Families.

Achenbach, T.M. \& Ruffle, T.M. (2000) The Child Behavior Checklist and related forms for assessing behavioural/emotional problems and competencies. Pediatrics in Review 21(8): 265-71.

Adshead, G., \& Fonagy, P. (2012). How does psychotherapy work? The self and its disorders. Advances in psychiatric treatment, 18, 242-249. doi: 10.1192/qpt.bp.111.009274

American Psychiatric Association. (2013). Diagnostic and statistical manual of mental disorders. (5 $5^{\text {th }}$ ed.) Arlington, VA: American Psychiatric Publishing.

Berant, E., \& Zim, S. (2013). Integration of Attachment Self-Report Scales with the Rorschach. Rorschachiana, 34, 156-187. doi: 10.1027/1192-5604/a000047

Conklin, A. C., Malone, J.C., \& Fowler, J. T. (2012). Mentalization and the Rorschach. Rorschachiana, 33, 189-213. doi: 10.1027/1192-5604/a000035

Exner, J. E., Jr. (2003). The Rorschach: A Comprehensive System (4th ed.). New York, NY: Wiley. Fonagy, P. \& Adshead, G. (2012). How mentalisation changes the mind. Advances in psychiatric treatment, 18, 353-362. doi: 10.1192/apt.bp.108.005876

Fonagy, P., Bateman, A. W., \& Luyten, P. (2012). Introduction and Overview. In: A. W. Bateman \& P. Fonagy (Eds.), Handbook of Mentalizing in Mental Health Practice (3-42). Washington, DC: 
American Psychiatric Publishing, Inc.

Fonagy, P., \& Target, M. (1998). Mentalization and the changing aims of child psychoanalysis.

Psychoanalytic Dialogues, 8(1), 87-114.

doi: $10.1080 / 10481889809539235$

Goodman, G. (2015). Interaction structures between a child and two therapists in the psychodynamic treatment of a child with borderline personality disorder. Journal of Child Psychotherapy. 41(2), 141 - 161. doi: $1 \underline{0.1080 / 0075417 X .2015 .1048124}$

Goodman, G. \& Athey-Lloyd, L. (2011). Interaction structures between a child and two therapists in the psychodynamic treatment of a child with Asperger's disorder. Journal of Child Psychotherapy, 37(3), 311-326. doi: 10.1080/0075417X.2011.614749

Goodman, G., \& Midgley, N. (2019). Child psychodynamic therapy: contemporary trends in treatment development. In: D. Kealy and J. S. Ogrodiniczuk (Eds.). Contemporary Psychodynamic Psychotherapy (pp. 237-252). London: Elsevier.

Goodman, G., Midgley, N., \& Schneider, C. (2016). Expert clinicians' prototypes of an ideal child treatment in psychodynamic and cognitive-behavioral therapy: Is mentalization seen as a common process factor? Psychotherapy Research, 26, 590-601.

doi: $1 \underline{0.1080 / 10503307.2015 .1049672}$

Goodman, G., Reed, P., \& Athey-Lloyd, L. (2015). Mentalization and Play Therapy Process Between Two Therapists and a Child with Asperger's Disorder. International Journal of Play Therapy, 24(1), 13-29. doi: $1 \underline{0.1037 / a 0038660}$

Halfon, S., Bekar, O., \& Gurleyen, B. (2017). An Empirical Analysis of Mental State Talk and Affect regulation in Two Single-Cases pf Psychodynamic Child Therapy. Psychotherapy, 54(2), 207219. doi: $1 \underline{0.1037 / p s t 0000113}$

Halfon, S., \& Bulut, P. (2019). Mentalization and the growth of symbolic play and affect regulation in psychodynamic therapy for children with behavioral problems, Psychotherapy Research, 29(5), 666-678. doi: 10.1080/10503307.2017.1393577

Halfon, S., Goodman, G., \& Bulut, P. (2018). Interaction structures as predictors of outcome in a naturalistic study of psychodynamic child psychotherapy, Psychotherapy Research, doi:10.1080/10503307.2018.1519267 
Hanley, T., \& Noble, J. (2017). Therapy outcomes: Is child therapy effective? In: N. Midgley, J. Hayes \& M. Cooper (eds.). Essential Research Findings in Child and Adolescent Counselling and Psychotherapy. (pp. 59-78). London: Sage Publications Ltd.

Hoffman, L., Rice, T., \& Prout, T. (2016). Manual of Regulation - Focused Psychotherapy for Children (RFP-C) With Externalizing Behaviors. New York: Routledge.

McLeod, J. (2010). Case Study Research in Counselling and Psychotherapy. London: Sage.

Midgley, N., Ensink, K., Lindqvist, K., Malberg, N., \& Muller, N. (2017). Mentalization-Based Treatment for Children. A Time-Limited Approach. Washington, DC: American Psychological Association.

Midgley, N., \& Kennedy, E. (2011). Psychodynamic psychotherapy for children and adolescents: a critical review of the evidence base. Journal of Child Psychotherapy, 37(3), 232-260. doi: $\underline{10.1080 / 0075417 X .2011 .614738}$

Midgley, N., O’Keeffe, S. O., French, L., \& Kennedy, E. (2017). Psychodynamic psychotherapy for children and adolescents: an updated narrative review of the evidence base. Journal of Child Psychotherapy, 43(3), 307-329. doi: 10.1080/0075417X.2017.1323945

Muñoz Specht, P., Ensink, K., Normandin, L., \& Midgley, N. (2016). Mentalization techniques used by psychodynamic therapists working with children and early adolescents. Bulletin of Menninger Clinic, 80(4), 281-315.doi: 1‥1521/bumc.2016.80.4.281

Palmer, R., Nascimento, L. N. \& Fonagy, P. (2013). The State of the Evidence Base for Psychodynamic Psychotherapy for Children and Adolescents. Child and Adolescent Psychiatric Clinical N Am, 22: 149-214. doi: 10.1016/j.chc.2012.12.001

Pineda, J. A., Giromini, L., Porcelli, P., Parolin, L., \& Viglione, D. J. (2011). Mu suppression and human movement responses to the Rorschach test. NeuroReport, 22(5), 223-226. doi: 10.1097/WNR.0b013e328344f45c

Porcelli, P., \& Kleiger, J. H. (2016). The "Feeling of Movement": Notes on the Rorschach Human Movement Response. Journal of Personality Assessment, 98(2), 124-134.doi: $1 \underline{0.1080 / 00223891.2015 .1102146 ~}$

Ramires, V. R. R, Carvalho, C., Schmidt, F. D., Fiorini, G. P., \& Goodman, G. (2015). Interaction Structures in the Psychodynamic Therapy of a Boy Diagnosed with Asperger's Disorder: A Single-Case Study. Research in Psychotherapy: Psychopathology, Process and Outcome, 18(2), 129-140. doi: 10.7411/RP.2015.112 
Ramires, V. R. R., Godinho, L. R., \& Goodman, G. (2017). The Therapeutic Process of a Child Diagnosed with Disruptive Mood Dysregulation Disorder. Psychoanalytic Psychology, 34, p. pap0000134. doi: 10.1037/pap0000134

Ribeiro, R. K. S. M., Semer, N. L., \& Yazigi, L. (2012). Rorschach comprehensive system data from a sample of 211 nonpatient children in Brazil. Journal of Personality Assessment, 94(3), 267-275. doi: $10.1080 / 00223891.2011 .653727$

Schmidt, F. D. Gastaud, M., \& Ramires, V. R. R. (2018). Interaction Structures in the Psychodynamic Psychotherapy of a Girl Diagnosed with Adjustment Disorder. Trends in Psychology, 26(2), 719734. doi: $10.9788 / \mathrm{tp} 2018.207 \mathrm{pt}$

Schneider, C. \& Jones, E. E. (2006). Child Psychotherapy Q-Set. Coding Manual. Berkeley: University of California. Unpublished Manual.

Schneider, C. \& Jones, E. E. (2012). Appendix IB. Child Psychotherapy Q-Set. Coding Manual. In: R. A. Levy, J. S. Ablon \& H. Kächele (Eds). Psychodynamic Psychotherapy Research: EvidenceBased Practice and Practice-Based Evidence. (pp 611-626). New York: Humana Press.

Schneider, C., Midgley, N. \& Duncan, A. (2010). A "Motion Portrait" of a Psychodynamic Treatment of an 11-Year-Old Girl: Exploring Interrelations of Psychotherapy Process and Outcome Using the Child Psychotherapy Q-Set. Journal of Infant, Child and Adolescent Psychotherapy, 9, 94-107. doi: $10.1080 / 15289168.2010 .510979$

Sharp, C., \& Venta, A. (2012). Mentalizing problems in children and adolescents. In: N. Midgley and I. Vrouva (Eds.) Minding the Child: Mentalization-Based Interventions with Children, Young People and their Families (pp. 35-53). London: Routledge.

Tessier, V. P., Normandin, L., Ensink, K., \& Fonagy, P. (2016). Fact or fiction? A longitudinal study of play and the development of reflective functioning. Bulletin of Menninger Clinic, 80(1), 60-79. doi: 10.1521/bumc.2016.80.1.60

Tuber, S. (2012). The Clinical Implications of Aspects of a Child's degree of Psychological Mindedness in Dynamically Oriented Child Psychotherapy. Journal of Infant, Child, and Adolescent Psychotherapy, 11, 3-20. doi: 1ㅁ.1080/15289168.2012.648886

Verheugt-Pleiter, A. J. E. (2008). Treatment strategy. In: Verheugt-Pleiter, A. J. E., Zelvalkink, J., \& Schmets, M. G. C. (Eds.) Mentalizing in children therapy (pp. 41-68). London: Karnac. 
Wielewicki, A., Gallo, A.E. \& Grossi, R. (2011) [Clinical practice instruments: CBCL as a functional analysis and intervention planning facilitator]. Trends in Psychology, 19(2): 513-23.

\section{Appendix}

\section{Assessment of children's baseline mentalizing capacity}

The Rorschach method was used as an instrument capable of researching and clinically evaluating many psychological processes involving mentalization (Berant \& Zim, 2013; Conklin et al., 2012; Zevalkink, 2008). Conklin et al. (2012) have defined a set of Rorschach variables, according to the Comprehensive System developed by Exner (2003), which have been investigated in some empirical studies, and that are hypothesized to assess aspects of psychological functioning that are crucial to mentalization. The authors proposed that texture variables $(T)$ could reflect the individual's ability to establish attachment bonds with others; human movement responses ( $\mathrm{M}$ and $\mathrm{M}-$-) would be related to empathic ability and social cognition; and the quality of the human response (GHR vs. PHR) would be related to the accuracy of perception of self and others as well as boundary disturbances, which relates to the mentalizing construct. According to the authors, based on empirical research, taken together, these variables can provide an image of a person's ability to mentalize.

Conklin et al. (2012) proposed three profiles describing different levels of mentalizing ability, based on specific combinations of Rorschach variables results. Profile $1(T=1, M+\geq 3$ ( $M+$ is the sum of $\mathrm{M}+$, Mo and $\mathrm{Mu}$ ), $\mathrm{M}-\leq 1, \mathrm{GHR}-\mathrm{PHR} \geq 1$ and $\mathrm{H} \geq 3$ ) describes a person with adequate mentalizing ability. He or she shows an accurate perception of himself or herself and the other with empathic ability and exhibits the capacity to understand and reflect on his or her own mental states and those of others. Profile $2(T>1, M->1$ or $M+<3, G H R-P H R<1$ and $H \geq 3)$ describes a person who 
presents mentalizing failures. He or she has poor empathic capacity and distorted and negative representations of self and other, indicating impairments in the ability to understand and reflect on one's and others' mental states. Profile $3(\mathrm{~T}=0, \mathrm{M}->1$ or $\mathrm{M}+<3, \mathrm{H}<2$ or $\mathrm{GHR}-\mathrm{PHR}<1)$ describes a person with impaired mentalization capacity characterized by a strong avoidance of understanding one's own and others mind, with limited interest in people and limited empathic ability.

In this study, the interpretation of the results was made in the context of the clinical evaluation of the children, the Rorschach's outcomes as a whole, and the Rorschach's variables related to the mentalizing construct. Table A1 summarizes the results in these specific variables:

Table A1

Children's outcomes in the variables assessing mentalization, according to the Rorschach Method

\begin{tabular}{|c|c|c|c|c|c|}
\hline Variables & $\begin{array}{l}\text { Alice's } \\
\text { Scores }\end{array}$ & $\begin{array}{l}\text { Peter's } \\
\text { Scores }\end{array}$ & $\begin{array}{c}\text { Expected scores for } \\
\text { nonclinical children } \\
\text { (Age 8) }\end{array}$ & $\begin{array}{l}\text { Walter's } \\
\text { Scores }\end{array}$ & $\begin{array}{c}\text { Expected scores for } \\
\text { nonclinical children } \\
\text { (Age 7) }\end{array}$ \\
\hline $\mathrm{M}$ & $3 \uparrow$ & 1 & $.79(\mathrm{SD}=.1 .20)$ & 1 & $.46(\mathrm{SD}=.89)$ \\
\hline $\mathrm{H}:(\mathrm{H})+\mathrm{Hd}+(\mathrm{Hd})$ & $1: 2 \uparrow$ & $1: 5 \uparrow$ & $\begin{array}{c}H: 1.11(S D=1.07) \\
(H)+H d+(H d): \\
.64(S D=.83)\end{array}$ & $1: 3 \uparrow$ & $\begin{array}{c}\mathrm{H}: .96(\mathrm{SD}=1.16) \\
(\mathrm{H})+\mathrm{Hd}+(\mathrm{Hd}): \\
.78(\mathrm{SD}=1.07)\end{array}$ \\
\hline COP & $1 \uparrow$ & 0 & $.19(\mathrm{SD}=.40)$ & 0 & $.08(\mathrm{SD}=.34)$ \\
\hline GHR : PHR & $3 \uparrow: 2$ & $1: \uparrow 5$ & $\begin{array}{l}\text { GHR: } 1.25(\mathrm{SD}=1.14) \\
\text { PHR: } 1.91(\mathrm{SD}=1.92)\end{array}$ & $2: 2$ & $\begin{array}{l}\text { GHR: } 1.34(S D=1.45) \\
\text { PHR: } 1.44(S D=1.11)\end{array}$ \\
\hline $\mathrm{Fd}$ & 0 & $1 \uparrow$ & $.25(\mathrm{SD}=.68)$ & $1 \uparrow$ & $.04(\mathrm{SD}=.28)$ \\
\hline Sum T & 0 & 0 & $.21(\mathrm{SD}=.49)$ & 0 & $.24(\mathrm{SD}=.62)$ \\
\hline Human content & 3 & $6 \uparrow$ & $2.85(\mathrm{SD}=2.24)$ & 4 & $2.68(\mathrm{SD}=1.87)$ \\
\hline Pure H & 1 & 1 & $1.11(\mathrm{SD}=1.07)$ & 1 & $.96(\mathrm{SD}=1.16)$ \\
\hline DQ+ & $7 \uparrow$ & $0 \downarrow$ & $2.74(\mathrm{SD}=2.44)$ & 0 & $1.90(\mathrm{SD}=2.05)$ \\
\hline DQv & 1 & 1 & $.75(\mathrm{SD}=1.07)$ & 0 & $.80(\mathrm{SD}=1.46)$ \\
\hline M- & 0 & $1 \uparrow$ & $.25(\mathrm{SD}=.48)$ & 0 & $.20(\mathrm{SD}=.57)$ \\
\hline$M_{+}$ & 0 & 0 & $.00(S D=.00)$ & 0 & $.00(S D=.00)$ \\
\hline Mo & $1 \uparrow$ & 0 & $.18(\mathrm{SD}=.44)$ & 0 & $.18(\mathrm{SD}=.44)$ \\
\hline $\mathrm{Mu}$ & $2 \uparrow$ & 0 & $.08(S D=.27)$ & 1 & $.08(\mathrm{SD}=.27)$ \\
\hline
\end{tabular}

Note. SD: standard deviation; $\uparrow$ increased result compared with the mean and standard deviation of the age group; $\downarrow$ decreased result compared with the mean and standard deviation of the age group; M: response in which human movement was determinant; $\mathbf{H}: \mathbf{( H ) +} \mathbf{H d}+\mathbf{H d})$ : ratio between responses of human content and responses of parahuman content and partial perceptions; COP: special code, indicating a trend to establish positive bonds; GHR : PHR: proportion between good human representations and poor human representations; Fd: responses of food content, indicate dependent behavior; Sum T: related to closeness and emotional contact; Human Content: total responses of human content; Pure H: responses of human content. Involves the percept of whole human form; DQ+: reflects the completion of analysis and synthesis processes; DQv: reflects immature information processing M-: response in which human movement was determinant and the formal quality was poor; indicates significant difficulties in thought; $\mathbf{M}_{+}$: response in which human movement was determinant and the formal quality was good; Mo: response in which human movement was determinant and the formal quality was ordinary; Mu: response in which human movement was determinant and the formal quality was unusual.

Table 1

Interaction Structures in the Three Case Studies, Internal Consistency, and Changes over Time

\begin{tabular}{ccc}
\hline Interaction Structure & $\begin{array}{c}\text { Internal } \\
\text { consistency }\end{array}$ & $\begin{array}{c}\text { Changes over } \\
\text { Time }\end{array}$ \\
\hline Alice, age 8, diagnosed with AD & \\
\hline
\end{tabular}




\begin{tabular}{|c|c|c|}
\hline $\begin{array}{l}\text { IS } 1 \text { - Attuned and interpretive T with active, expressive and demanding C } \\
\text { IS } 2 \text { - Sensitive and supportive T with withdrawn and distant C } \\
\text { IS } 3 \text { - Didactic, directive T with aggressive and defensive C } \\
\text { IS } 4 \text { - Directive and limiting T with dependent, resistant and ashamed C } \\
\text { IS } 5 \text { - Receptive and supportive T with anxious C }\end{array}$ & $\begin{array}{l}\alpha=.81 \\
\alpha=.85 \\
\alpha=.83 \\
\alpha=.78 \\
\alpha=.76\end{array}$ & $\begin{aligned} r= & .41^{* \star \uparrow} \\
--- & -- \\
r= & -.53^{\star *} \downarrow \\
r= & .35^{* \uparrow}\end{aligned}$ \\
\hline \multicolumn{3}{|l|}{ Peter, age 8, diagnosed with ASD } \\
\hline $\begin{array}{l}\text { IS } 1 \text { - Resistant and defensive } C \text { with uncertain, unresponsive and didactic } \\
T \text { }\end{array}$ & $\alpha=.95$ & $r=-.52^{* *} \downarrow$ \\
\hline $\begin{array}{l}\text { IS } 2 \text { - Active, confident and lively } \mathrm{C} \text {, competing with connected and } \\
\text { reflective T }\end{array}$ & $\alpha=.88$ & $r=.39^{\star * \uparrow}$ \\
\hline IS 3 - Articulated C seeking proximity with an active and not neutral $T$ & $\alpha=.74$ & --- \\
\hline IS 4 - Provocative, hostile $\mathrm{C}$ with reassuring and accepting $\mathrm{T}$ & $\alpha=.65$ & --- \\
\hline \multicolumn{3}{|l|}{ Walter, age 7, diagnosed with DMDD } \\
\hline $\begin{array}{l}\text { IS } 1 \text { - Connected C, attached to T, expressing mental contents and } \\
\text { fantasies, with a supportive T }\end{array}$ & $\alpha=.94$ & --- \\
\hline IS 2 - Sensitive, accepting and supportive T with an understood C & $\alpha=.84$ & --- \\
\hline IS 3 - Directive and didactic T with a $\mathrm{C}$ aware of his difficulties & $\alpha=.82$ & $r=.78^{\star * \uparrow}$ \\
\hline IS 4 - Demanding, competitive and blaming $\mathrm{C}$ with a supportive $\mathrm{T}$ & $\alpha=.67$ & --- \\
\hline
\end{tabular}

Note. T: therapist; C: Child; $: p<.05 ;{ }^{\star \star}: p<.01 ; \uparrow:$ IS became more characteristic over time; $\downarrow:$ IS became less characteristic over time. 